\title{
Journal of Nanotechnology and Materials Science
}

\section{Synthesis and Optical Properties of Bisporphyrin Conjugated with Naphthalene Bisimide}

\author{
Kazuya Ogawa ${ }^{1 *}$, Takefumi Yotsutuji ${ }^{2}$
}

${ }^{1}$ Graduate Faculty of Interdisciplinary Research, Faculty of Engineering, University of Yamanashi, 4-3-11 Takeda, Kofu, Yamanashi 400-8511

${ }^{2}$ Graduate School of Materials Science, Nara Institute of Science and Technology, 8916-5 Takayama, Ikoma, Nara 630-0101, Japan

*Corresponding author: Kazuya Ogawa, Graduate Faculty of Interdisciplinary Research, Faculty of Engineering, University of Yamanashi, 4-3-11 Takeda, Kofu, Yamanashi 400-8511; E-mail: kogawa@yamanashi.ac.jp

Citation: Kazuya Ogawa., et al. Synthesis and Optical Properties of Bisporphyrin Conjugated with Naphthalene Bisimide. (2017) J Nanotechnol Material Sci 4(1): 14-18.
Received date: February 20, 2017

Accepted date: March 28, 2017

Published date: April 12, 2017

DOI: $10.15436 / 2377-1372.17 .1375$

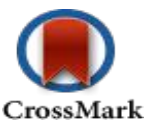
for bisporphyrin without electron acceptor.

\section{Introduction}

Two-Photon Absorption (TPA) is a nonlinear optical phenomenon which occurs through simultaneous absorption of two photons. Because of quadratic dependence on the incident light intensity in the TPA process, the efficiency becomes largest at the focal point, allowing a variety of optical applications such as three-dimensional optical memory[1], two-photon Photodynamic Therapy (PDT)[2], and optical limiting[3]. Porphyrin is a potential candidate for TPA materials because of its large $\pi$-conjugated electron system. But simple porphyrins have only small $\sigma^{(2)}$ values less than a few tens of GM $\left(1 \mathrm{GM}=10^{-50} \mathrm{~cm}^{4} \mathrm{~s}\right.$ molecule $^{-1}$ photon $^{-1}$ ).

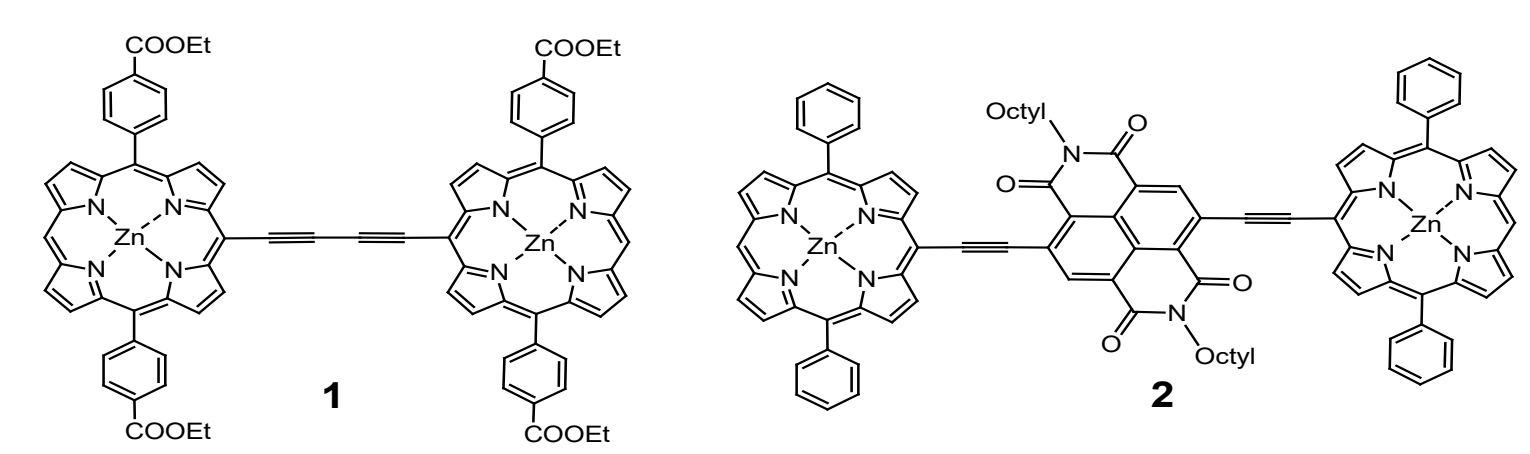

We reported that butadiyne-linked bisporphyrin 1 as shown Scheme 1 showed an effective TPA cross section value (eff ${ }_{\sigma}^{(2)}$ ) of 7,700 GM[4]. The large enhancement is mainly achieved by the expansion of $\pi$-conjugation between porphyrins by linking with triple bonds. To obtain insights into a further increase of the eff $\sigma_{\sigma}^{(2)}$ value, it is interesting to introduce an electron acceptor group to a conjugated bisporphyrin in order to polarize the molecule. Here, we report synthesis and preliminary optical properties of novel ethylene-linked bisporphyrin 2 having naphthalene bisimide as an electron acceptor at the central part of the molecule. Such the D-A-D type structure is not common in the molecular systems with porphyrin. (Scheme 1)

Scheme 1: Structures of bisporphyrins 1 and 2.

Copyrights: (C) 2017 Kazuya Ogawa. This is an Open access article distributed under the terms of Creative Commons Attribution 4.0 International License. 


\section{Materials and Methods}

\section{General procedures}

${ }^{1} \mathrm{H}$ NMR spectra were recorded on JEOL JNM-ECP 600 spectrometer. Chemical shifts are reported on $\delta$ scale with respect to TMS as an internal standard. Coupling constants $(\mathrm{J})$ are reported in Hertz (Hz). UV-vis spectra were measured by a Shimadzu UV-3100 PC spectrometer. Fluorescence spectra were recorded using a Hitachi F-4500 spectrometer. MALDI-TOF mass spectra were obtained with a PerSeptive-Biosystems Voyager-DE STR spectrometer with dithranol as a matrix. TLC was performed on analytical glass TLC plates silica gel coated with 60 F254 (E. Merck). Column chromatography was performed using a column packed with either silica gel $60 \mathrm{~N}$ (Kanto Chemical, spherical, neutral, 63-210 $\mu \mathrm{m})$. Preparative GPC was conducted using Japan Analytical Industry LC-908 (column; TSK gel $\mathrm{G} 3000 \mathrm{H}$, eluent; pyridine). Isocyanuric acid (95\%), bromine (99\%), octyl amine (98\%), trifluoroacetic acid (98\%), $\mathrm{CHCl}_{3}$ (99\%), triethylamine (99\%), N-bromosuccinimide (98\%), zinc acetate dihydrate (99\%), THF (99.5\%), $\mathrm{Pd}\left(\mathrm{PPh}_{3}\right)_{2} \mathrm{Cl}_{2}(98 \%)$, and $\mathrm{AsPh}_{3}(95 \%)$ were purchased from Wako Pure Chemical Industries. Chloranil (97\%) was purchased from Nacalai tesque.

\section{Synthesis}

\section{Dibromoisocyanuric acid (4)}

Isocyanuric acid $(5.16 \mathrm{~g}, 0.04 \mathrm{~mol}), \mathrm{LiOH}(1.92 \mathrm{~g}, 0.08$ $\mathrm{mol})$, and bromine $(25.6 \mathrm{~g}, 0.16 \mathrm{~mol})$ were added into $400 \mathrm{ml}$ of water. After stirring for 2 hours, the reaction solution was cooled in refrigerator for 24 hours, and then white solid was separated by filtration to afford the title compound (84\%). ${ }^{1} \mathrm{H}$ NMR (600 $\left.\mathrm{MHz}, \mathrm{DMSO}-\mathrm{d}_{6}\right) \delta 11.1(\mathrm{~s}, \mathrm{NH})$.

\section{2,6-Dibromonaphthalene tetracarboxylic dianhydride $(5)^{[5]}$}

A solution of $3(1.0 \mathrm{~g}, 3.73 \mathrm{mmol})$ in $6 \mathrm{ml}$ of sulfuric acid was slowly added into a solution of $4(2.14 \mathrm{~g}, 7.46 \mathrm{mmol})$ in $6 \mathrm{ml}$ of sulfuric acid. After heating for 15 hours at $130^{\circ} \mathrm{C}$, the reaction solution was added into ice. The precipitate formed was separated by filtration to afford $5(84 \%)$. ${ }^{1} \mathrm{H}$ NMR $(600 \mathrm{MHz}$, DMSO-d $) \delta 8.78(\mathrm{~s})$.

\section{N,N-dioctyl-2,6-dibromonaphthalene tetracarboxylic acid bisimide (6) ${ }^{[5]}$ \\ Octyl amine $(0.62 \mathrm{ml}, 3.76 \mathrm{mmol})$ was added into a solution of 5 (400 mg, $0.94 \mathrm{mmol}$ ) in $32 \mathrm{ml}$ of acetic acid. After stirring for 2 hours at $130^{\circ} \mathrm{C}$, the reaction solution was added into ice. The precipitate formed was separated by filtration, and then purified by silica gel column chromatography $\left(\mathrm{CHCl}_{3}\right)$ to give $6(24 \%)$. ${ }^{1} \mathrm{H}$ NMR $\left(600 \mathrm{MHz}, \mathrm{CDCl}_{3}\right) \delta 8.99(\mathrm{~s}, 2 \mathrm{H}), 4.19$ (m, 4H), $1.73(\mathrm{~m}, 4 \mathrm{H}), 1.26-1.43(\mathrm{~m}, 20 \mathrm{H}), 0.88(\mathrm{~m}, 6 \mathrm{H})$.}

\section{5,15-Diphenylporphyrin (9)}

Trifluoroacetic acid $(0.6 \mathrm{ml})$ was added to a solution of dipyrromethane 7[6] (500 mg, $3.42 \mathrm{mmol})$ and 8 (727 mg, $6.85 \mathrm{mmol}$ ) in $600 \mathrm{~mL}$ of $\mathrm{CHCl}_{3}$. After stirring for $16 \mathrm{~h}$ at room temperature, triethylamine $(1.2 \mathrm{ml})$ and chloranil $(2.54 \mathrm{~g}, 10.3$ mmol) were added. After stirring for $5 \mathrm{~h}$, the crude material was concentrated and purified by silica gel column chromatography (hexane/ $\left.\mathrm{CHCl}_{3}=1: 1\right)$ to give $9(15 \%)$. TLC (hexane/ $\mathrm{CHCl}_{3}$ $=1: 1) \mathrm{R}_{\mathrm{f}}=0.30 ;{ }^{1} \mathrm{H} \mathrm{NMR}\left(600 \mathrm{MHz}, \mathrm{CDCl}_{3}\right) \delta 10.3(\mathrm{~s}, 2 \mathrm{H}), 9.37$ $(\mathrm{d}, 4 \mathrm{H}, \mathrm{J}=4.8 \mathrm{~Hz}$ ), 9.07 (d, 4H, J = 4.8 Hz), 8.26 (m, 4H), 7.76$7.80(\mathrm{~m}, 6 \mathrm{H}),-3.12(\mathrm{~s}, 2 \mathrm{H}, \mathrm{NH})$; MALDI-TOF Mass $\mathrm{C}_{32} \mathrm{H}_{22} \mathrm{~N}_{4}$ Calcd: 462.2; Found: 462.5.

\section{5,15-Diphenyl-20-bromoporphyrin (10)}

N-bromosuccinimide (50 $\mathrm{mg}, 0.28 \mathrm{mmol}$ ) was added to a solution of $9(86 \mathrm{mg}, 0.19 \mathrm{mmol})$ in $15 \mathrm{~mL}$ of $\mathrm{CHCl}_{3}$ at $-40^{\circ} \mathrm{C}$. After stirring for $15 \mathrm{~min}, 5 \mathrm{~mL}$ of acetone was added. The reaction solution was evaporated and subjected to silica gel column chromatography (hexane $/ \mathrm{CHCl}_{3}=1: 1$ ) to yield $48 \mathrm{mg}$ of 10 (48\%). TLC (hexane $\left./ \mathrm{CHCl}_{3}=1: 1\right) \mathrm{R}_{\mathrm{f}}=0.6 ;{ }^{1} \mathrm{H} \mathrm{NMR}(600 \mathrm{MHz}$, $\left.\mathrm{CDCl}_{3}\right) \delta 10.1(\mathrm{~s}, 1 \mathrm{H}), 9.73(\mathrm{~d}, 2 \mathrm{H}, \mathrm{J}=4.2 \mathrm{~Hz}), 9.26(\mathrm{~d}, 2 \mathrm{H}, \mathrm{J}=$ $4.2 \mathrm{~Hz}), 8.95(\mathrm{~m}, 4 \mathrm{H}), 8.21(\mathrm{~d}, 4 \mathrm{H}, \mathrm{J}=6.6 \mathrm{~Hz}), 7.77-7.82(\mathrm{~m}$, $6 \mathrm{H}),-3.01(\mathrm{~s}, 2 \mathrm{H}, \mathrm{NH})$; MALDI-TOF Mass $\mathrm{C}_{32} \mathrm{H}_{21} \mathrm{BrN}_{4}$ Calcd: 540.1; Found: 542.8.

\section{5,15-Diphenyl-20-bromozincporphyrin (11)}

Bromoporphyrin 10 (93 mg, $0.17 \mathrm{mmol})$ was dissolved in $\mathrm{CHCl}_{3}(40 \mathrm{~mL})$ and $10 \mathrm{~mL}$ of a saturated solution of zinc acetate dihydrate in $\mathrm{MeOH}$ was added. After stirring for 30 minutes, the mixture was washed with saturated aqueous $\mathrm{NaHCO}_{3}$ and water (96\%). 1H NMR (600 MHz, $\left.\mathrm{CDCl}_{3}\right) \delta 10.2(\mathrm{~s}, 1 \mathrm{H}), 9.80$ $(\mathrm{d}, 2 \mathrm{H}, \mathrm{J}=4.2 \mathrm{~Hz}), 9.35(\mathrm{~d}, 2 \mathrm{H}, \mathrm{J}=4.2 \mathrm{~Hz}), 9.03(\mathrm{~m}, 4 \mathrm{H}), 8.20$ $(\mathrm{d}, 4 \mathrm{H}, \mathrm{J}=6.0 \mathrm{~Hz}), 7.75-7.80(\mathrm{~m}, 6 \mathrm{H})$; MALDI-TOF Mass $\mathrm{C}_{32} \mathrm{H}_{19} \mathrm{BrN}_{4} \mathrm{Zn}$ Calcd: 602.0; Found: 603.1.

\section{5,15-Diphenyl-20-trimethylsilylethynylzincporphyrin (12)}

A vacuum-dried Schlenk flask was charged with bromozincporphyrin $11\left(89 \mathrm{mg}, 1.5 \times 10^{-7} \mathrm{~mol}\right)$ and filled with argon. Dry THF $(12 \mathrm{~mL})$, triethylamine $(2.4 \mathrm{~mL}), \mathrm{Pd}\left(\mathrm{PPh}_{3}\right)$ ${ }_{2} \mathrm{Cl}_{2}\left(5.6 \mathrm{mg}, 1.8 \times 10^{-5} \mathrm{~mol}\right), \mathrm{CuI}\left(0.74 \mathrm{mg}, 9 \times 10^{-6} \mathrm{~mol}\right)$, and TMS-acetylene $(70 \mu \mathrm{l})$ were added into the flask under argon atmosphere. After stirring for 4 hours at room temperature in the dark, the reaction mixture was washed with saturated aqueous $\mathrm{NH}_{4} \mathrm{Cl}$ and water, and extracted with $\mathrm{CHCl}_{3}$. The crude product was purified by silica gel column chromatography $\left(\mathrm{CHCl}_{3}\right)$ to give $72.8 \mathrm{mg}$ of 15 as a red solid $(78 \%) .{ }^{1} \mathrm{H} \mathrm{NMR}(600 \mathrm{MHz}$, $\left.\mathrm{CDCl}_{3}\right) \delta 10.2(\mathrm{~s}, 1 \mathrm{H}), 9.80(\mathrm{~d}, 2 \mathrm{H}, \mathrm{J}=4.8 \mathrm{~Hz}), 9.34(\mathrm{~d}, 2 \mathrm{H}, \mathrm{J}$ $=4.8 \mathrm{~Hz}), 9.03(\mathrm{~m}, 4 \mathrm{H}), 8.22(\mathrm{~d}, 4 \mathrm{H}, \mathrm{J}=6.0 \mathrm{~Hz}), 7.78-7.81$ $(\mathrm{m}, 6 \mathrm{H}), 0.62(\mathrm{~s}, 9 \mathrm{H})$; MALDI-TOF Mass $\mathrm{C}_{37} \mathrm{H}_{28} \mathrm{~N}_{4}$ SiZn Calcd: 620.1; Found: 620.6.

\section{5,15-Diphenyl-20-ethynylzincporphyrin (13)}

In a vacuum-dried Schlenk flask under an argon atmosphere, a $1 \mathrm{M}$ THF solution of Tetrabutylammonium fluoride $(0.51 \mathrm{ml}, 0.51 \mathrm{mmol})$ was added to a solution of $12(72.8 \mathrm{mg}$, $0.12 \mathrm{mmol})$ in chloroform $(25 \mathrm{~mL})$. After stirring for $30 \mathrm{~min}$ utes at room temperature, water was added and extracted with chloroform. The crude was purified by silica gel column chromatography $\left(\mathrm{CHCl}_{3}\right)$ to give $51.4 \mathrm{mg}$ of $13(78 \%)$ as a red solid. ${ }^{1} \mathrm{H}$ NMR $\left(600 \mathrm{MHz}, \mathrm{CDCl}_{3}\right) \delta 10.3(\mathrm{~s}, 1 \mathrm{H}, \mathrm{d}), 9.83(\mathrm{~d}, 2 \mathrm{H}, \mathrm{J}=$ $4.8 \mathrm{~Hz}), 9.35(\mathrm{~d}, 2 \mathrm{H}, \mathrm{J}=4.8 \mathrm{~Hz}), 9.05(\mathrm{~m}, 4 \mathrm{H}), 8.32(\mathrm{~d}, 4 \mathrm{H}, \mathrm{J}=$ $6.0 \mathrm{~Hz}), 7.79$ - $7.82(\mathrm{~m}, 6 \mathrm{H}), 9.05(\mathrm{~m}, 1 \mathrm{H})$; MALDI-TOF Mass $\mathrm{C}_{24} \mathrm{H}_{20} \mathrm{~N}_{4} \mathrm{Zn}$ Calcd: 548.1; Found: 549.1 .

\section{Target 2}

In a vacuum-dried Schlenk flask under an argon atmosphere, porohyrin $13\left(38 \mathrm{mg}, 6.9 \times 10^{-5} \mathrm{~mol}\right), 6(20.4 \mathrm{mg}, 3.14$ $\left.\times 10^{-5} \mathrm{~mol}\right), \mathrm{Pd}_{2}(\mathrm{dba})_{3}\left(16.3 \mathrm{mg}, 1.57 \times 10^{-5} \mathrm{~mol}\right)$, and $\mathrm{AsPh}_{3}$ $\left.\left(19.2 \mathrm{mg}, 6.28 \times 10^{-5} \mathrm{~mol}\right)\right)$ were dissolved in anhydrous THF 
$(26 \mathrm{~mL})$ and triethylamine $(4.7 \mathrm{ml})$. After stirring for 2 hours at room temperature, water was added and extracted with chloroform. The solution was washed with saturated aqueous $\mathrm{NH}_{4} \mathrm{Cl}$ and water. The crude was purified by preparative GPC to give $10.3 \mathrm{mg}$ of target $(21 \%)$ as a brown solid. MALDI-TOF Mass $\mathrm{C}_{111} \mathrm{H}_{123} \mathrm{~N}_{10} \mathrm{O}_{4} \mathrm{Zn}_{2}$ Calcd: 1582.5; Found: 1584.5.

\section{Measurement of nonlinear absorption}

The effective two-photon absorption measurements were performed using an optical parametric oscillator (Continuum Surelight OPO) pumped with a THG beam $(355 \mathrm{~nm})$ from a Q-switched Nd:YAG laser (Continuum Surelight I-10)[4, 7a, 8]. The pulse width and the repetition rate were $5 \mathrm{~ns}$ and $10 \mathrm{~Hz}$, respectively. The incident laser light was focused by a plano-convex lens $(\mathrm{f}=100 \mathrm{~mm}$ ) giving a beam waist of around $0.035 \mathrm{~mm}$. The sample solution was placed in a $2 \mathrm{~mm}$ quartz cuvette and stirred using a magnetic bar during the measurement.

\section{Results and Discussion}

Synthetic routes for the target molecule 2 are shown in Scheme 2. First, naphthalene-1,4,5,8-tetracarboxylic dianhydride was brominated using 4, which was prepared from isocyanuric acid with $\mathrm{LiOH}$ and bromine, to afford 5[5]. Diimide 6 was synthesized by the reaction of 5 with octyl amine[5]. Dipyrromethane 7 was prepared according to the literature[6]. Porphyrin 9 was synthesized from 7 and 8 using trifluoroacetic acid in $15 \%$ yield. Monobromoporphyrin 10 was prepared from 9 using 1.5 equivalents of $\mathrm{N}$-Bromosuccinimide (NBS) at $-40^{\circ} \mathrm{C}$ in $48 \%$ yield. Bromoporphyrin 10 was metalated by zinc acetate to give 11. TMS-ethynylzincporphyrin 12 was obtained from 11 by the reaction with TMS-acetylene using a $\mathrm{Pd}(\mathrm{PPh})_{2} \mathrm{Cl}_{2} /$ $\mathrm{CuI}$ catalytic system in THF/triethylamine (TEA) in 78\% yield. The TMS group in 12 was deprotected using TBAF to afford 13. The cross-coupling reaction of 13 and 6 was conducted by using $\mathrm{Pd}_{2}(\mathrm{dba})_{3} / \mathrm{AsPh}_{3}$ as a catalyst system at room temperature to obtain the target 2, which was isolated using preparative Gel Permeation Chromatography (GPC) using pyridine as an eluent. The yield of the target was $21 \%$. The purity and identification were confirmed by analytical GPC and MALDI-TOF mass, as shown in Figures 1. (Scheme 2) Figure 2 shows one-photon absorption spectrum of 2 in pyridine. The Soret and Q bands appeared at around 440 and $790 \mathrm{~nm}$, respectively, which were redshifted compared with those of 12 indicating expansion of $\pi$-conjugation between porphyrins. The nonlinear absorption measurement was performed using a nanosecond open-aperture Z-scan method at a wavelength range from 960 to 1060 $\mathrm{nm}$, where one-photon absorption was negligible. Figure 3 inset shows typical Z-scan trace of $5 \times 10^{-6} \mathrm{M}$ in pyridine at $980 \mathrm{~nm}$ with theoretically fitted curves according to the following equations[7]. In this figure, normalized transmittances were plotted as a function of the sample position, $\mathrm{z}$, and the dip was observed around the focal position due to nonlinear absorption.

$$
T(\zeta)=\frac{(1-R)^{2} e^{\left(-\alpha^{(1)} L\right)}}{\sqrt{\pi} q(\zeta)} \int_{-\infty}^{\infty} \ln \left[1+q(\zeta) e^{\left(-x^{2}\right)}\right] d x
$$

(2)

$$
\begin{aligned}
& q(\zeta)=\frac{q_{0}}{1+\zeta^{2}} \\
& \text { (2) } \mathrm{q}_{0}=\alpha^{(2)}(1-\mathrm{R}) \mathrm{I}_{0} \mathrm{~L}_{\text {eff }} \\
& \text { (3) } \mathrm{L}_{\text {eff }}=[1-\exp (-\alpha(1) \mathrm{L})] / \alpha(1) \\
& \text { (5) } \mathrm{eff}_{\sigma}^{(2)}=\hbar \omega \alpha^{(2)} / \mathrm{N}
\end{aligned}
$$

where $\zeta$ denotes the normalized z-position $\left(\zeta=\left(\mathrm{z}-\mathrm{z}_{0}\right) / \mathrm{z}_{\mathrm{R}}\right)$, and $\mathrm{z}_{0}$ and $z_{R}$ mean the focal position and the Rayleigh range, respectively. $\alpha^{(1)}$ denotes a one-photon absorption coefficient and $\mathrm{R}$ is the Fresnel reflectance. L denotes the light path length $(2 \mathrm{~mm})$ and $\alpha^{(2)}$ denotes the 2PA coefficient. Leff is the effective path length and $\mathrm{I}_{0}$ denotes the peak intensity at the focal position. $\mathrm{N}$ is the number density of the molecule and $\hbar \omega$ is the photon energy of the incident light. Finally, the effective TPA cross section value eff $_{\sigma}{ }^{(2)}$ was calculated using equation (5). (Figure 3)

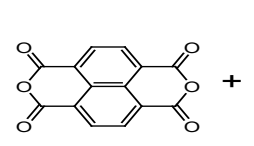

3
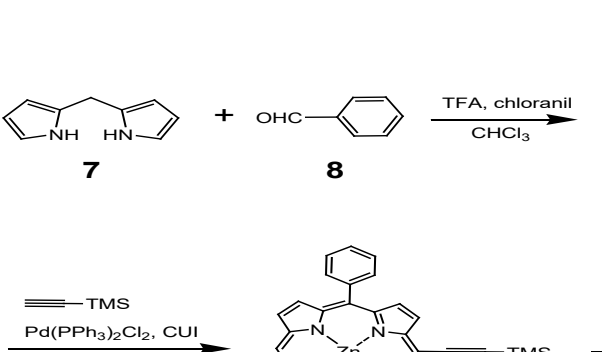
$\mathrm{Pd}\left(\mathrm{PPh}_{3}\right)_{2} \mathrm{Cl}_{2}, \mathrm{CUI}$ THF / TEA
8

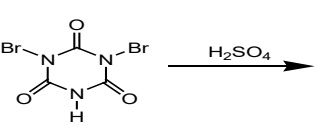

4

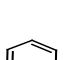

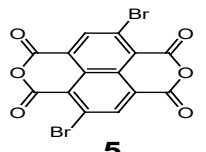

5
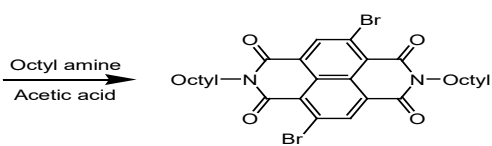

6
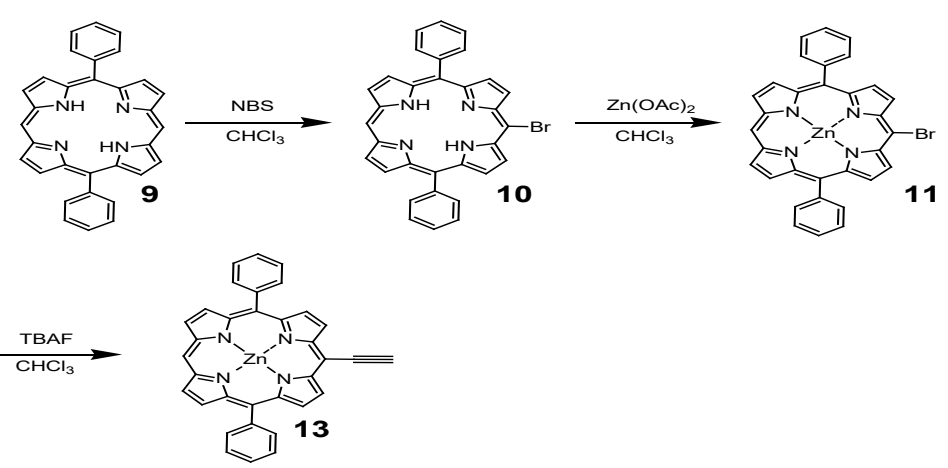
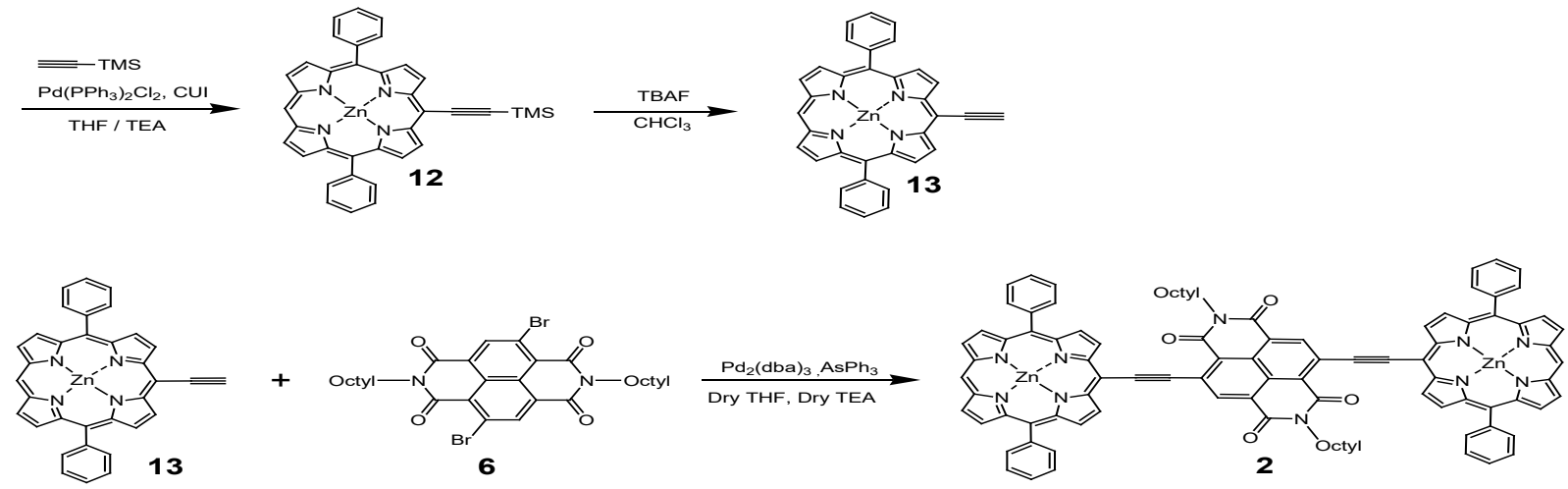

Scheme 2: Synthetic route for 2. 


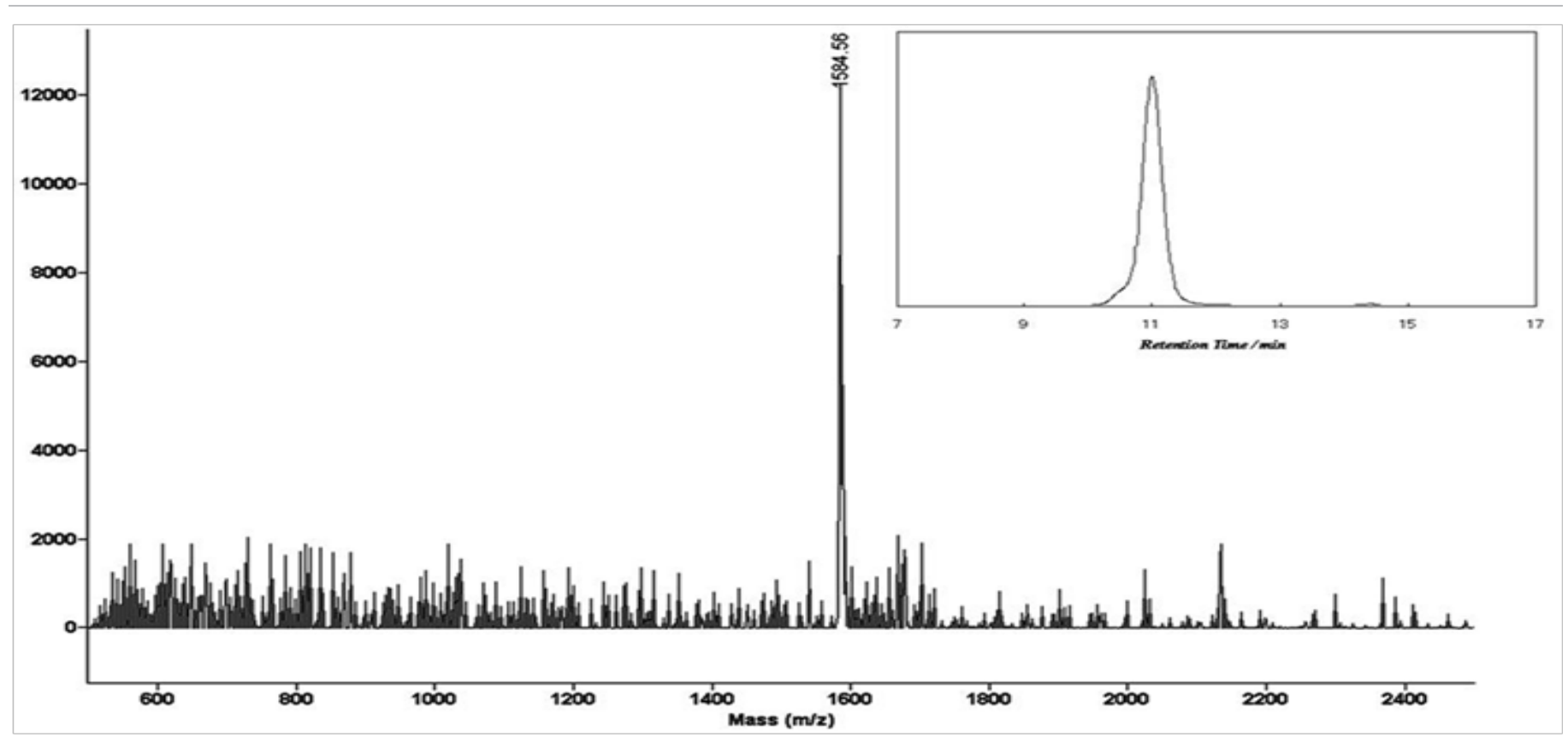

Figure 1: MALDI-TOFF mass and analytical GPC (inset) charts of 2.

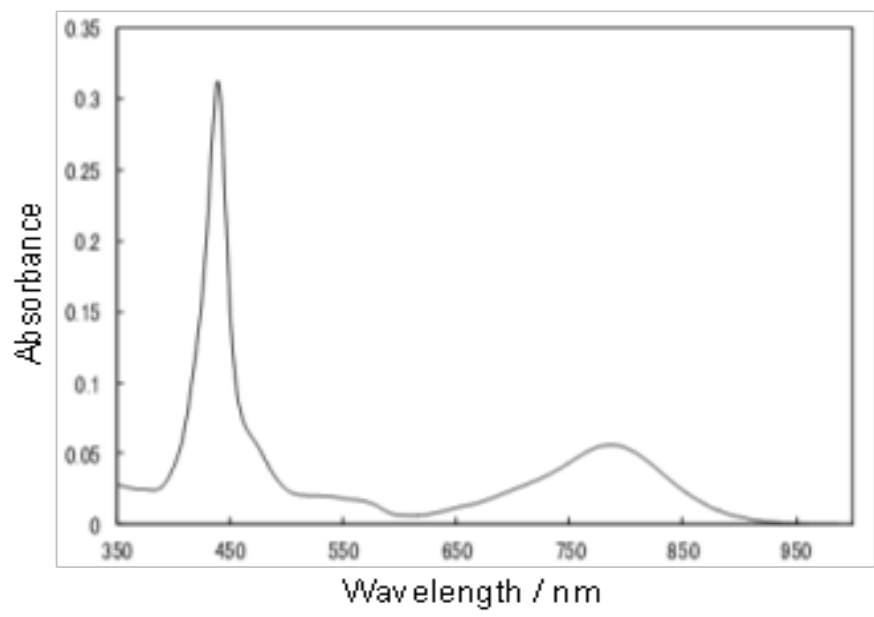

Figure 2: Absorption spectrum of 2 in pyridine.

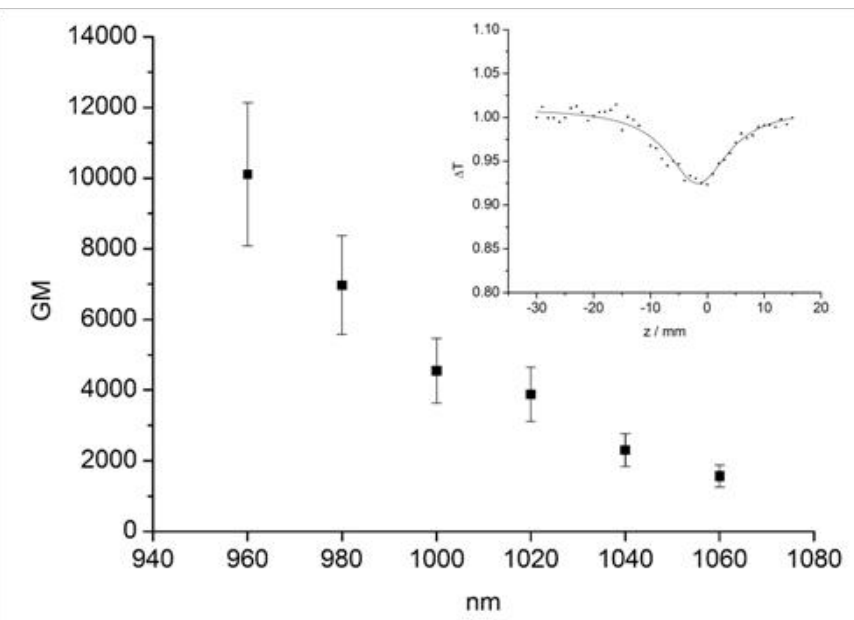

Figure 3: Effective TPA spectra of 2 measured using nanosecond pulses in pyridine and typical open-aperture Z-scan traces at $980 \mathrm{~nm}$ (inset).
$900 \mathrm{~nm}$ that was almost twice as long as those of the Soret band due to the existence of one-photon absorption. Although the peak could not be obtained for 2, the eff ${ }_{\sigma}^{(2)}$ value obtained for 2 at $960 \mathrm{~nm}$ is 1.3 times larger than that for 1 . In general, the eff ${ }_{\sigma}^{(2)}$ value measured using nanosecond laser pulses is $2-3$ orders of magnitude larger than that obtained with femtosecond pulses because of the contribution of excited state absorption (ESA) to the signal. This effect is difficult to separate from the pure TPA signal. Therefore, the values obtained in this study cannot be compared with the pure $\sigma^{(2)}$ values measured using femtosecond pulses, which were reported in most literatures. Even if the reported values were measured using nanosecond pulses, the fair comparison is difficult because the ESA contributions are different between the compound systems. However, in some applications using TPA materials (such as TPA-PDT or the creation of 3-D optical memory devices), a laser with a nanosecond pulse may be more appropriate because of the easiness of operation and availability. For this reason, we consider it important to examine the nonlinear absorption properties using nanosecond pulses.

\section{Conclusion}

We have successfully synthesized novel ethynylene-linked bisporphyrin conjugated with naphthalene bisimide as an electron acceptor by palladium-catalyzed cross-coupling reaction. The purity and identification were confirmed by analytical GPC and MALDI-TOF mass. One-photon absorption spectra showed the red-shifted Soret and Q bands, indicating expansion of $\pi$-conjugation The maximum eff ${ }_{\sigma}^{(2)}$ value including the ESA contribution was observed as $10100 \mathrm{GM}$ at $960 \mathrm{~nm}$ measured using a nanosecond Z-scan method. This value was 1.3 times larger than the value obtained for bisporphyrin without electron acceptor.

The maximum eff ${ }_{\sigma}^{(2)}$ value was obtained as $10100 \pm$ $2000 \mathrm{GM}$ at $960 \mathrm{~nm}$. The peak could not be measured at around 


\section{Acknowledgments}

This work was supported by Grant-in-Aids for Scientific Research (C) (No. 15K05471) from Ministry of Education, Culture, Sports, Science and Technology, Japan (Monbu Kagakusho).

\section{References}

1. Parthenopoulos, A., Rentzepis, P.M. Three-dimensional optical storage memory. (1989) Science 245(4920): S843-S845.

Pubmed | Crossref | Others

2. Strickler, H., Webb, W.W. Three-dimensional optical data storage in refractive media by two-photon point excitation. (1991) Opt Lett 16(22): S1780-S1782.

Pubmed | Crossref| Others

3. Wachter, A., Partridge, W.P., Fisher, W.G., et al. Simultaneous two-photon excitation of photodynamic therapy agents. (1998) Proc SPIE-Into Soc Opt Eng 3269: S68-S74.

Others

4. Bhawalkar, J.D., Kumar, N.D., Zhao, C.F., et al. Two-photon photodynamic therapy. (1997) Clin Laser Med Surg 15(5): S201-S204.

Pubmed

5. Nonlinear Optics of Organic Molecules and Polymers. (1996) CRC Press: Boca Raton.

Others

6. Ogawa, K., Dy, J., Kobuke, Y. Substituent effect on two-photon absorption properties of conjugated porphyrins. (2005) Porphyrins Phthalocyanines 9(10): S735-S744.

Crossref|Others

7. Chaignon, F., Falkenström, M., Karlsson, S., et al. Very large acceleration of the photoinduced electron transfer in a Ru(bpy) ${ }_{3}$-naphthalene bisimide dyad bridged on the naphthyl core. (2007) Chem Commun (1): S64-S66

Pubmed | Crossref | Others
8. Laha, J.K., Dhanalekshmi, S., Taniguchi, M., et al. A Scalable Synthesis of Meso-Substituted Dipyrromethanes. (2003) Org Process Res Dev 7(6): S799-S812.

Crossref| Others

9. Ogawa, K., Ohashi, A., Kobuke, Y., et al. Two-photon absorption properties of self-assemblies of butadiyne-linked bis(imidazolylporphyrin). (2005) J Phys Chem B 109(46): S22003-S22012. Pubmed | Crossref | Others

10. Audebert, P., Kamada, K., Matsunaga, K., et al. The third-order NLO properties of $\mathrm{D}-\pi$-A molecules with changing a primary amino group into pyrrole. (2003) Phys Lett 367(1-2): S62-S71.

Others

11. Antonov, L., Kamada, K., Ohta, K., et al. A systematic femtosecond study on the two-photon absorbing $\mathrm{D}-\pi$-A molecules $-\pi$-bridge nitrogen insertion and strength of the donor and acceptor groups. (2003) Phys Chem Chem Phys 5(6): S1193-S1197.

Crossref|Others

12. Dy, T., Ogawa, K., Satake, A., et al. Water-soluble self-assembled butadiyne-bridged bisporphyrin: a potential two-photon-absorbing photosensitizer for photodynamic therapy. (2007) Chem Eur J 13(12): S3491-S3500.

Pubmed | Crossref| Others

13. Tanihara, J., Ogawa, K., Kobuke, Y. Two-photon absorption properties of conjugated supramolecular porphyrins with electron donor and acceptor. (2006) J Photochem Photobiol A 178(2-3): S140-S149.

Crossref|Others
Ommega Online Publishers

Journal Title: Journal of Nanotechnology and Materials Science Journal Short Name: J Nanotech Mater Sci
Journal ISSN: 2377-1372

E-mail: nanoscience@ommegaonline.com

Website: www.ommegaonline.org 